Document downloaded from:

http://hdl.handle.net/10251/70463

This paper must be cited as:

V.Genovés; Borrachero Rosado, MV.; Soriano Martinez, L.; Eiras Fernández, JN.; Paya Bernabeu, JJ. (2015). Preliminary study on short-term sulphate attack evaluation by nonlinear impact resonance acoustic spectroscopy technique. Construction and Building Materials. 78:295-302. doi:10.1016/j.conbuildmat.2015.01.016.

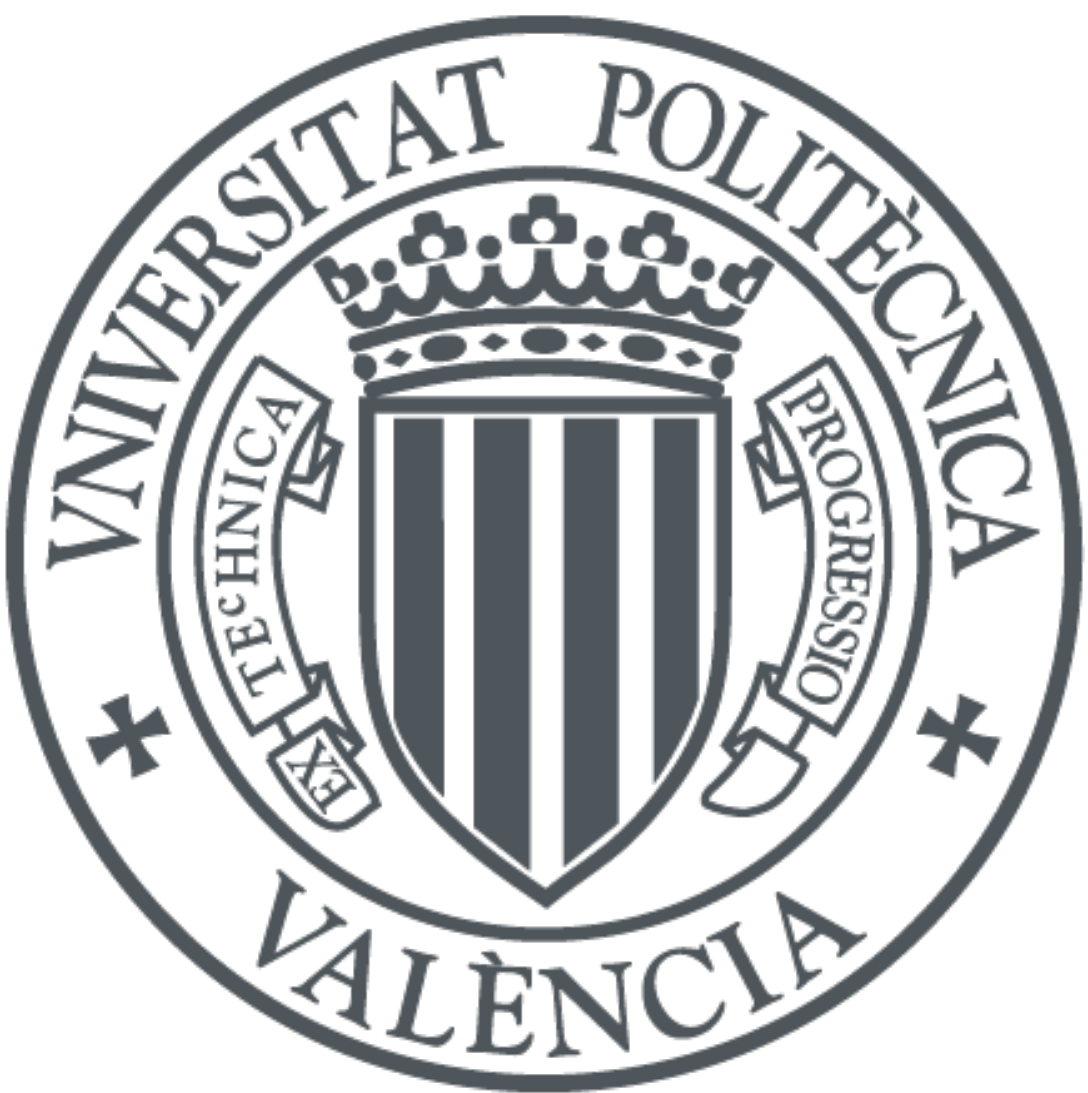

The final publication is available at

http://dx.doi.org/10.1016/j.conbuildmat.2015.01.016

Copyright Elsevier

Additional Information 


\title{
Preliminary study on short-term sulphate attack evaluation by non-linear impact resonance acoustic spectroscopy technique
}

\author{
V.Genovés $^{\mathrm{a}, *}$, L.Soriano ${ }^{\mathrm{a}}$, M.V.Borrachero ${ }^{\mathrm{a}}$, J.Eiras ${ }^{\mathrm{a}}$, J.Payáa \\ ${ }^{a}$ ICITECH, Universitat Politècnica de València, Camino de Vera, s/n 46022 Valencia, Spain
}

\begin{abstract}
The scope of this paper is to study the sulphate attack on concrete with new testing methods based on vibrational spectroscopy with mechanical waves. These are based on Non-linear Impact Resonance Acoustic Spectroscopy (NIRAS) that allows detecting the frequency shift of its resonant modes. Both, signal quality factor and alpha, are measured to monitor the increase of the non-linearity of the material due to the stiffness change on the matrix after being attacked. Different Portland cement matrices were assessed and results between vibrational tests and the traditional expansion ASTM method were compared. Two types of cement with different $\mathrm{C}_{3} \mathrm{~A}$ content were tested for external sulphate attack and one cement with high $\mathrm{C}_{3} \mathrm{~A}$ content with different amount of addition of $\mathrm{SO}_{3}$ on the original mix was tested for internal attack. NIRAS was suitable for monitoring external sulphate attack process. A microstructual analysis was carried out with thermogravimetry (TG), scanning electron microscopy (SEM) and X-ray diffraction (XRD) techniques in order to detect harmful products on damaged series.
\end{abstract}

Keywords: concrete, non-linear spectroscopy, sulphate attack, damage, frequency shift

\section{Introduction}

Ettringite is an expansive compound formed during the Portland cement hydration process (primary ettringite, eq.1) and also during the lifetime of the concrete structures (secondary ettringite, eq.2) [1]. Primary ettringite has no harmful effect on concrete because expansions produced by the reaction are absorbed by fresh concrete. Secondary ettringite is formed for months, or even years after concrete has been hardened. The stresses that appear when an external or internal source of sulphate salts reacts with calcium aluminates hydrates can spoil the matrix, causing micro cracks, expansion and spalling. Additionally gypsum is also formed by reaction of sulphate and portlandite (Eq.3).

\footnotetext{
*Corresponding author E-mail adress: genoves.gomez@gmail.com
} 


$$
\begin{aligned}
\mathrm{C}_{3} \mathrm{~A}+\left(\mathrm{CaSO}_{4} \cdot 2 \mathrm{H}_{2} \mathrm{O}\right)+26 \mathrm{H}_{2} \mathrm{O} & \longrightarrow 3 \mathrm{CaSO}_{4} \cdot 3 \mathrm{CaO} \cdot \mathrm{Al}_{2} \mathrm{O}_{3} \cdot 32 \mathrm{H}_{2} \mathrm{O} \\
3 \mathrm{CaSO}_{4} \cdot 2 \mathrm{H}_{2} \mathrm{O}+\mathrm{C}_{3} \mathrm{~A} \cdot 6 \mathrm{H}_{2} \mathrm{O}+24 \mathrm{H}_{2} \mathrm{O} & \longrightarrow 3 \mathrm{CaSO}_{4} \cdot 3 \mathrm{CaO} \cdot \mathrm{Al}_{2} \mathrm{O}_{3} \cdot 32 \mathrm{H}_{2} \mathrm{O} \\
\mathrm{Ca}(\mathrm{OH})_{2}+\mathrm{SO}_{4}^{-2}+2 \mathrm{H}_{2} \mathrm{O} & \longrightarrow \mathrm{CaSO}_{4} \cdot 2 \mathrm{H}_{2} \mathrm{O}+2 \mathrm{OH}^{-}
\end{aligned}
$$

Initially, sulphate products fill the voids, capillary net and also promote a compressive resistance increment [2]. When the voids and free space inside the element are full, micro cracks start to appear and compressive strength and Young's modulus decrease. When this mechanism is too aggressive, the cement paste could loss strength and adhesion capacity due to decalcification of C-S-H [3]. On one hand, external sulphate attack (ESA) is determined by the chemical interaction between sulphate-rich sources with the cement paste. The sulphate anion may be contained on soils and water as different sulphate salts such as sodium, potassium, magnesium and calcium $[1,2]$. The next three conditions must be satisfied for ESA [1]

- Porous cement matrix

- Presence of water

- High percentage of $\mathrm{SO}_{3}$

If any of the above conditions are not fulfilled ESA does not occur. For instance, if concrete structure's foundation is placed on sulphate-rich soil having high humidity or containing groundwater but the cement matrix is not porous enough, then the sulphate external attack will not occur.

On the other hand, internal sulphate attack (ISA) is due to an initial content of $\mathrm{SO}_{3}$ in high percentages on the original mix or in raw materials. Also, combined sulphates on clinker are released slowly when they are in a liquid phase with possibility to form ettringite and other expansive compounds. It damages the matrix if enough sulphate were added to the initial mix. The next two conditions must be satisfied for ISA [1]

- High percentage of $\mathrm{SO}_{3}$ in the original matrix

- Presence of water

Traditional methods to detect damage and expansion of the material were used in this experimental program following the ASTM standard [4]. These techniques evaluate the potential expansion of a mortar bar for fifteen weeks as it remains immersed in a $\mathrm{Na}_{2} \mathrm{SO}_{4}$ solution. During the last few years, alternative methods with termogravimetry and XRD on cement/pozzolane systems [5-9], numerical models [10] and also micrography techniques in real structures [11] had been developed in order to detect and monitor damage due to sulphate attack on concrete and mortar elements.

Several authors focused their research on characterizing concrete matrices with different NDT techniques. Garnier et al. were studying different concrete matrices with varying $\mathrm{w} / \mathrm{c}$ ratio, compressive strength and density 
using non destructive testing techniques, such as pressure waves, surface waves, back-scattered waves, impact echo and non linear analysis [12]. Gudra and Stawiski, used surface waves to study the influence of surface roughness and inclination angle on the measurement of the concrete specimens [13].

It is known that NDT techniques have the capability of obtaining a widerange of physical properties of cementitious materials like dynamic Young's modulus, porosity and compressive strength [14-18].

Leśnicki et al. and Chen et al. studied alkali-silica reaction on concrete and mortar showing several changes of non-linear parameters for damaged specimens $[19,20]$. Those authors monitored the microcracking process evaluating the frequency shift of its resonant vibrational modes using Non-linear Impact Resonance Acoustic Spectroscopy (NIRAS) method. This technique was developed by Chen et al. who used a cantilevered test disposition for mortar specimens to excite the principal modes and evalute the non linear effects on the frequency. A subsequent study by Leśnicki et al. used a free vibration specimen configuration to evaluate the same parameters of concrete specimens showing better results with this model.

The scope of this paper is to compare two methods (traditional expansion test and NIRAS) in order to evaluate sulphate attack on Portland cement matrices with different $\mathrm{C}_{3} \mathrm{~A}$ content.

\section{Experiment}

Several tests were done on this study in order to compare the performance of NIRAS tests and other characterization techniques. Expansion tests (Mitutoyo digital indicator $0.001 \mathrm{~mm}$ resolution), Scanning Electron Microscopy (JEOL JSM 6300 aplying a 20kV voltage), Thermogravimetry and X-ray diffraction. On thermogravimetry analyses, portions of the samples were taken and pulverized with an agate mortar adding a small amount of acetone. The solid was filtered and dried at $60^{\circ} \mathrm{C}$ for 15 minutes. The equipment used were a Mettler TGA 850. Sealed aluminium crucibles of $100 \mu \mathrm{m}$ were used with a lid that has a micro hole to create a water vapour self-generated atmosphere. The analysis was carried out in dry nitrogen atmosphere with a flow of $75 \mathrm{~mL} / \mathrm{min}$, a heating rate of $10{ }^{\circ} \mathrm{C} / \mathrm{min}$, and a temperature interval of 35 to $300{ }^{\circ} \mathrm{C}$. For high resolution thermogravimetric analysis (MaxRes), the lowest heating rate was $0.1^{\circ} \mathrm{C} / \mathrm{min}$ and the highest one $10^{\circ} \mathrm{C} / \mathrm{min}$. The heating rate was changed according to the mass loss rate. The Highest heating rate was achieved for mass loss rate lower than $1 \mu \mathrm{g} \mathrm{s}^{-1}$, and the lowest heating rate was achieved for mass loss rate higher than $3 \mu \mathrm{g} \mathrm{s}^{-1}$. The X-ray diffractometer model used is a Brucker AXS D8 Advance. $\mathrm{K} \alpha$ of Cu radiation was used and secondary monochromator ( $\mathrm{Ni}$ filter) that eliminates the $\mathrm{Cu} \mathrm{K} \beta$ radiation. The intensity and voltage generator $\mathrm{x}$-ray tube was set to $20 \mathrm{KV}$ and $40 \mathrm{~mA}$ respectively. Diffractograms were recorded for $2 \Theta$ range between $5^{\circ}$ and $70^{\circ}$ with a step angle of 0.02 and 2 seconds accumulation time.

\subsection{Materials}

As commented earlier, the main sulphate attack process is the formation of secondary ettringite due to free $\mathrm{SO}_{4}^{-2}$ ions on the solution and calcium aluminate hydrates on the cement matrix. Other variable for this mechanism is the porosity of the cement matrix. 
Table 1: Dosages (in grams) used to manufacture the specimens in grams

\begin{tabular}{llllllll}
\hline & \multicolumn{2}{l}{ ESA } & & & & \multicolumn{2}{l}{ ISA } \\
\cline { 2 - 4 } \cline { 7 - 8 } Code & $0.5-\mathrm{G}$ & $0.5-\mathrm{W}$ & $0.6-\mathrm{G}$ & $0.6-\mathrm{W}$ & & $0.6-0 \%$ & $0.6-3 \%$ \\
\hline $\mathrm{w} / \mathrm{c}$ & 0.5 & 0.5 & 0.6 & 0.6 & 0.6 & 0.6 \\
$\mathrm{Sand}$ & 1350 & 1350 & 1350 & 1350 & & 1350 & 1350 \\
\%SO $_{3}$ & - & - & - & - & 0 & 3 \\
Cement type & $\mathrm{SR}$ & $\mathrm{BL}$ & $\mathrm{SR}$ & $\mathrm{BL}$ & $\mathrm{BL}$ & $\mathrm{BL}$ \\
\hline
\end{tabular}

For that reason, for ESA investigation two types of cement to prepare mortars with two different $\mathrm{w} / \mathrm{c}$ ratios (tables 1 and 2) were chosen, while for ISA study one cement type and two different amounts of addition of $\mathrm{SO}_{3}$ (by adding anhydrous $\mathrm{CaSO}_{4}$ ) in the original mix were considered.

Table 2 shows the chemical composition of every type of cement used on this experiment. The main difference between the two cements is the $\mathrm{C}_{3} \mathrm{~A}$ content: the sulphate resistant cement was a Spanish cement CEM I-52,5 SR and it has $2.33 \%$ of $\mathrm{C}_{3} \mathrm{~A}$ and the white cement, BL II A-LL $42.5 \mathrm{R}$, has $9.84 \% \mathrm{C}_{3} \mathrm{~A}$.

Table 2: Cement composition by \% weight

\begin{tabular}{llllllllllll}
\hline Cement type & $\mathrm{LOI}^{*}$ & $\mathrm{SiO}_{2}$ & $\mathrm{Al}_{2} \mathrm{O}_{3}$ & $\mathrm{Fe}_{2} \mathrm{O}_{3}$ & $\mathrm{CaO}$ & $\mathrm{MgO}$ & $\mathrm{SO}_{3}$ & $\mathrm{C}_{4} \mathrm{AF}$ & $\mathrm{C}_{3} \mathrm{~A}$ & $\mathrm{C}_{3} \mathrm{~S}$ & $\mathrm{C}_{2} \mathrm{~S}$ \\
\hline CEM I-52,5 SR & 2.05 & 20.52 & 3.37 & 3.92 & 63.36 & 1.96 & 2.59 & 11.93 & 2.33 & 55.7 & 16.94 \\
BL II A-LL 42.5 R & 9.75 & 16.55 & 3.88 & 0.26 & 62.91 & 1.39 & 4.28 & 0.8 & 9.84 & 51.73 & 8.56 \\
\hline
\end{tabular}

" Loss on ignition

The specimens prepared for the tests had different geometries: $40 \times 40 \times 160 \mathrm{~mm}^{3}$ for vibrational tests (three

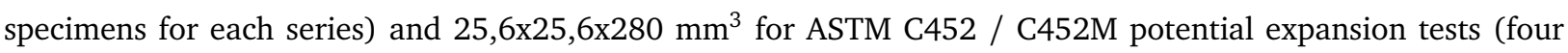
specimens for each series). The sulphate solution had $15 \%$ of $\mathrm{Na}_{2} \mathrm{SO}_{4}$.

\subsection{NIRAS method and test disposition}

NIRAS method is a relatively new NDT technique which can detect changes in materials from the resonance frequency shifts of the vibrational modes of a specimen made from this material as the impact energy increases [20] This change is simply due to the non-linearity of the material. This technique has been shown to be highly sensitive to material defects, specifically to the micro-cracks of the material. It is well-known that defects in a material can be detected from the vibrational frequency resonance values of a specimen made of that material. Distributed cracks reduce the stiffness of the specimen, and therefore, the natural frequency of the structural element made of that material. Besides this linear effect $(f=\sqrt{k / m}$, where $k$ is the stiffness and $m$ the mass of the specimen) cracks also change non-linear properties of the material: Those cracks form imperfect matrix and non-homogeneity zones and thus creates, for instance, pores or voids, micro pores, paste-aggregate interface and other mesoscopic effects $[19,20]$.

This kind of imperfections trigger non-linear effects such as change of the frequency when the impact energy is increased, non linear modulation of two waves and scalability loss. This distortion of the elastic waves is 
responsible for the change in the observed resonance frequency in NIRAS tests, which can be described as a non-linear hysteretic macroscopic behavior of the material itself [19].

According to the phenomenological model for hysteresis and classical non-linear constitutive relations proposed by Van Den Abeele et al.[21], the elastic modulus for a material with non-linear effects can be represented as eq 4:

$$
E=E_{0}\left[1+\beta \epsilon+\delta \epsilon^{2}+\alpha(\Delta \epsilon+\epsilon \operatorname{sgn}(\dot{\epsilon}))\right]
$$

where $\mathrm{E}_{0}$ is the linear elastic modulus, $\beta$ and $\delta$ are the coefficients of cubic and quartic anharmonicities, $\Delta \epsilon$ is the strain amplitude variation, $\epsilon$ and $\dot{\epsilon}$ are the strain and strain rate, $\alpha$ is the measure of hysteresis, and sgn is the sign function [21]. Specimens made with these materials that follow eq. 4 change their natural vibration frequencies with the variation of the excitation energy. This non-linearity could be defined as follows (eq. 5)

$$
\frac{f_{0}-f}{f_{0}}=\alpha \Delta \epsilon
$$

where $f_{0}$ is the frequency for the low impact energy, $f$ the frequency for the high impact energy, $\alpha$ the measure of non-linearity and $\epsilon$ the deformation suffered by the specimen. In this experiment, 10 impacts were given for every NIRAS test. After collecting ten signals with different impact energies and identifying the peaks in the frequency domain a first order polynomial was fitted to obtain the $\mathrm{R}^{2}$ of the line as a measure of the reliability of the hysteretic parameter.

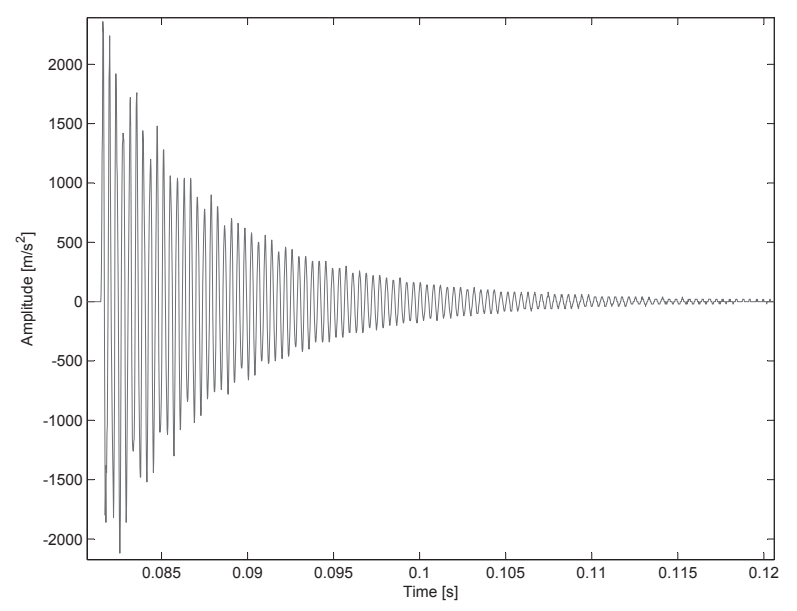

Figure 1: Typical time domain acceleration signal

In figure 1 is shown a typical acceleration signal in time domain captured with the sensor on a prismatic specimen after being beaten with the impact hammer. This signal shows a damped behaviour typical of one 
degree of freedom systems that follows (eq 6)

$$
A(t)=A_{i} e^{-\xi \omega t}
$$

Where $A_{i}$ is the initial amplitude $\xi$ the damping ratio, $\omega$ the natural frequency of the system and $t$ the time.

After capturing raw data, the signal is processed with Fast Fourier Transform (FFT) to obtain the complete vibrational spectrum to evaluate linear and non-linear parameters. In figure 2 is shown two different specimens (damaged and undamaged) where it can observe the frequency shift (non-linearity increasing) in an obvious way.

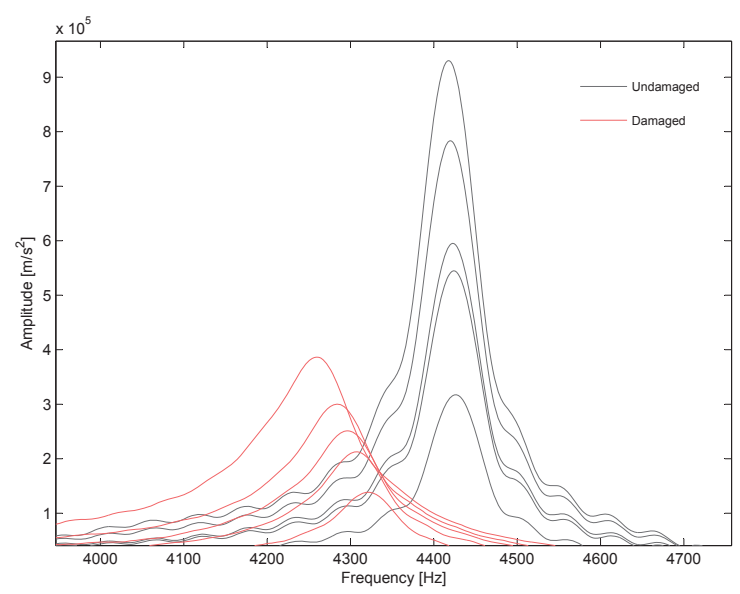

Figure 2: Frequency domain signal of a damaged and undamaged specimens on NIRAS test

Figure 3 shows the test disposition used for the experiment. It be made up of hammer support, instrumented impact hammer with an additional weight, accelerometer sensor, a foam-coated support and an axis that allows the hammer to strike the specimen with different levels of energy. Mortar specimen was $40 \times 40 \times 160 \mathrm{~mm}^{3}$. A laptop and a pre-amplifier for acquiring and amplifying signals was used.

\section{Results and discussion}

\subsection{Internal sulphate attack (ISA)}

ISA tests were performed first to obtain high rates of damage at a relatively short ages. Due to this aggressive attack, the specimens were measured at short time intervals both for expansion tests and NIRAS.

\subsubsection{ISA expansion measures}

As comented earlier, expansion measures where taken following the ASTM C452 / C452M standard.

Figure 4 shows the dimensional increment due to an internal attack on mortar bars. On one hand, mortar specimens with $3 \%$ of $\mathrm{SO}_{3}$ addition shows important expansions at short period of time due to the rapid formation of the secondary ettringite. Specimens with no $\mathrm{SO}_{3}$ addition on the initial mix shows no appreciable dimensional increment as expected. 


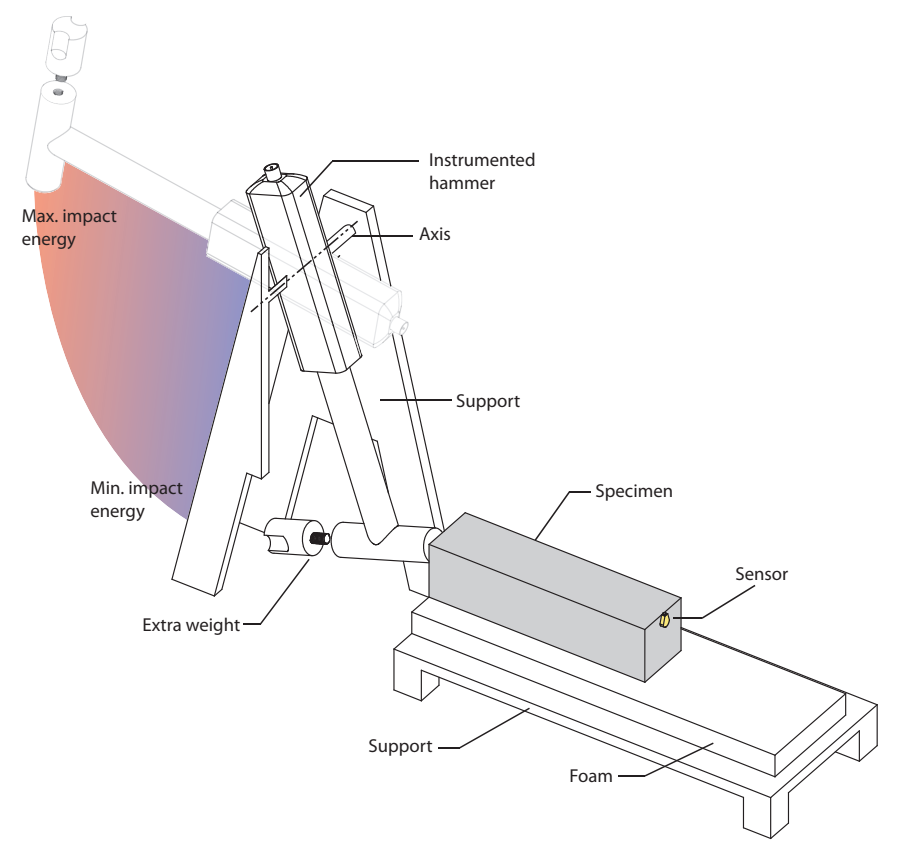

Figure 3: NIRAS test layout

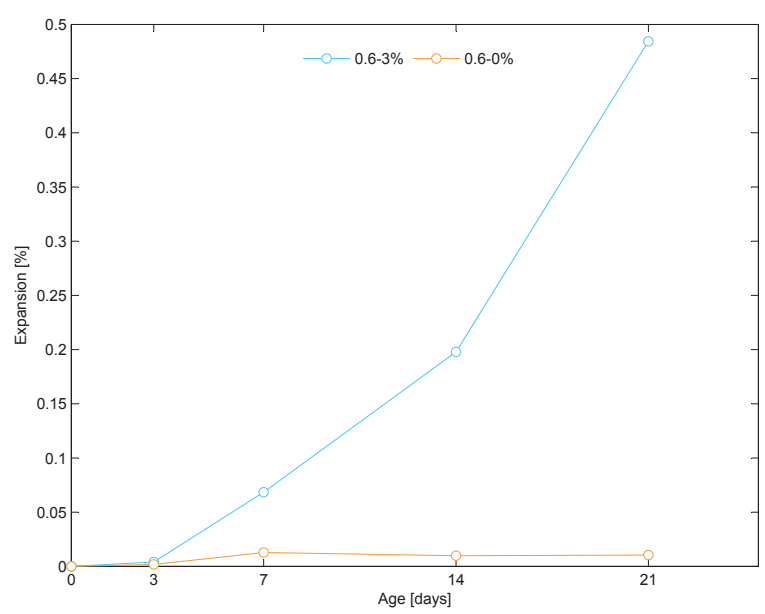

Figure 4: Average expansion measures on ISA specimens

\subsubsection{ISA NIRAS measures}

After obtaining the expansion results NIRAS measures were performed. With this non destructive test several parameters could be determined: Non linearity parameter on first flexural mode $\alpha_{1 \text { flex }}$, the natural frequency of resonance for the same impact level $\mathrm{f}_{1 \text { flex }}$ and the quality parameter $\mathrm{Q}_{1 \text { flex }}$ of the wave [14].

Figure 5 shows the frequency domain signals for two ISA specimens. Blue series is from $0 \% \mathrm{SO}_{3}$ addition and gray series is from $3 \% \mathrm{SO}_{3}$ addition to the original mix. 


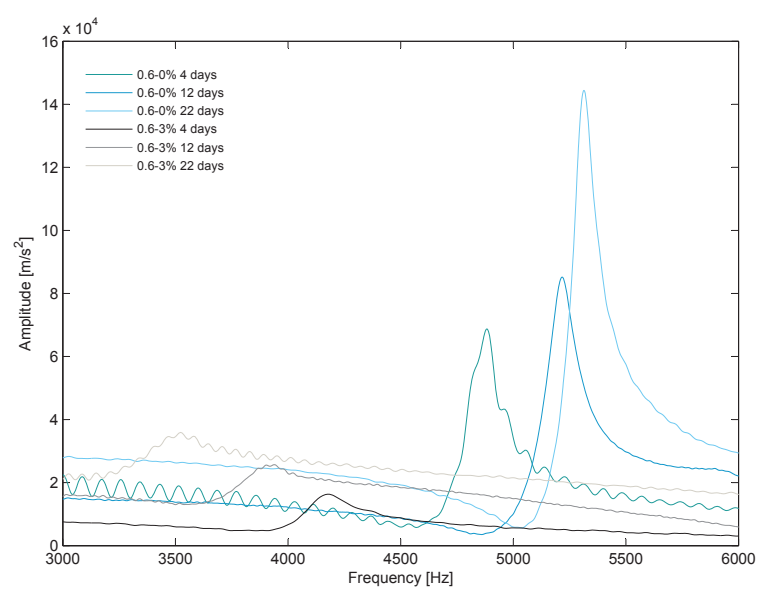

Figure 5: Highest energy impact frequency domain signals for two ISA specimens

As can be observed, 0.6-0\% specimens show a frequency increase for the same impact level its resonant vibration mode as the time progresses due to the hydration. However, $0.6-3 \%$ specimens show a decrease of its resonant mode frequency due to the important expansions despite being hit with the same impact energy level. It is also important to highlight the differences between the amplitude and $\mathrm{Q}_{\text {factor }}$ of the signal for the same impact level. The frequency is proportional to the elastic modulus as commented before. The amplitude and $\mathrm{Q}_{\text {factor }}$ of the signal increase when the material micro structure improves, that also increases the vibration frequency.

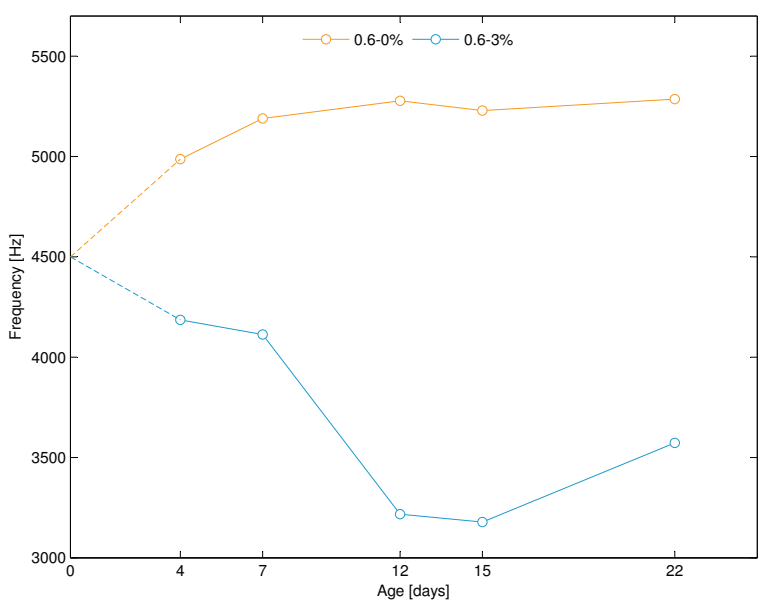

Figure 6: Frequency variation on ISA specimens

Frequency was measured for different curing ages under wet chamber conditions ( $100 \% \mathrm{RH}$ and $\left.20^{\circ} \mathrm{C}\right)$ in order to obtain at least linear parameters of highly damaged specimens. Figure 6 shows frequency variations on all measured ages. As was explained before on spectrum response, as curing age increases, frequency of undamaged series also increases. Nevertheless, highly damaged specimens decrease its frequency as the curing 
age increases. It is important to highlight that all specimens should have the same fundamental frequency at $t=0$. For this reason, non linear parameter evaluation is not suitable for extreme damage evaluation due to the low amplitudes and $\mathrm{Q}_{\text {factor }}$ of peaks on fundamental modes at high energy impacts.

\subsubsection{ISA microstructure analysis}

After performing all non destructive tests, the specimens were broken and samples were taken to analyse the microstructure with Scanning Electron Microscopy (SEM) and thermogravimetry.

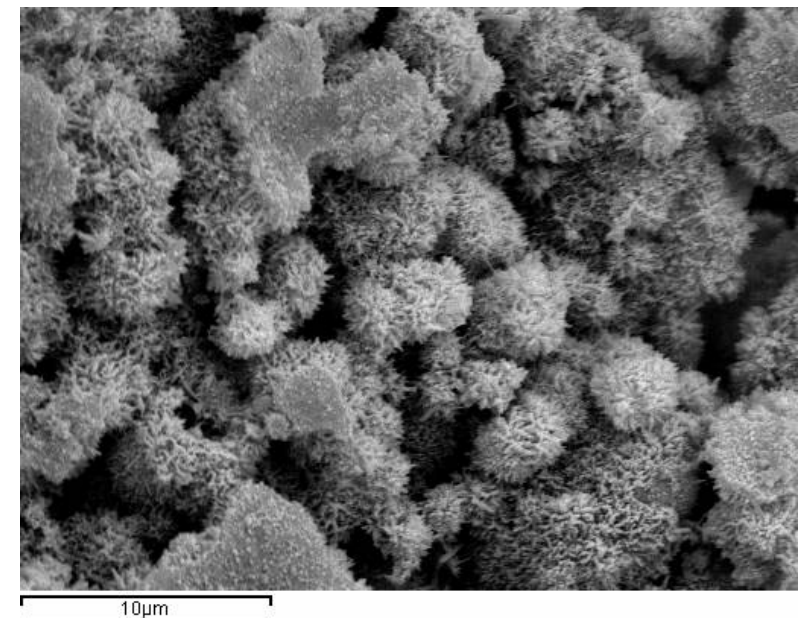

(a) ISA specimen with $3 \%$ of $\mathrm{SO}_{3}$ addition on the initial mix

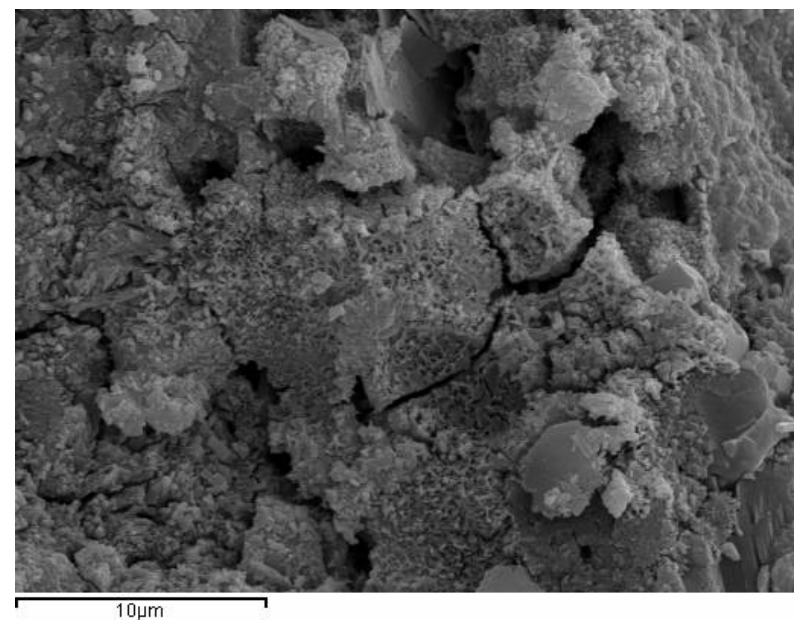

(b) ISA specimen with $0 \%$ of $\mathrm{SO}_{3}$ addition on the initial mix

Figure 7: SEM images $\mathrm{x} 4000$ magnification of specimens with and without $\mathrm{CaSO}_{4}$ addition

Figure 7 shows SEM images, of ISA samples taken from $0.6-3 \%$ and $0.6-0 \%$ specimens. On figure $7 \mathrm{~b}$ it can be see a non spoiled matrix without any ettringite formation or other harmful products, while on figure 7a appeared a totally different microstructure with a large formation of ettringite. This images justify the huge and rapid expansion of 0.6 - 3\% specimens and associated frequency response spectra.

Thermogravimetric analyses were performed on pastes with the same dosage (without aggregate). Figure 8 shows DTG curves of pastes cured for 28 days on wet chamber at $20^{\circ} \mathrm{C}$. In this figure it can be noticed the ettringite peak that appears on 140 to $160{ }^{\circ} \mathrm{C}$ range [22]. 0.6 - $0 \%$ series have a little peak on this range of temperatures while 0.6 - $3 \%$ have a huge one on this range. Thus, the large amount of expansive products was justified for $0.6-3 \%$ series.

XRD was performed on $0.6-3 \%$ series in order to detect ettringite formation on damaged samples. A large amount of sand was easily removed from the crushed mortar by sieving.

In figure 16 it can be observed XRD diffractogram for 0.6-3\% sample. It can be noticed the presence of calcite (from limestone filler present in white Portland cement), quartz due to the remaining sand in the original mix and ettringite formed during the process of specimen degradation. 


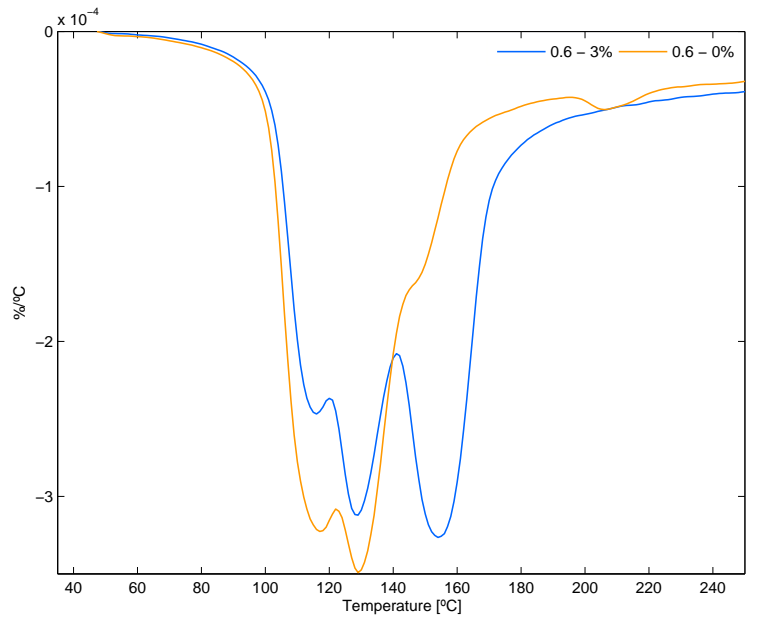

Figure 8: DTG curves of $0.6-3 \%$ and $0.6-0 \%$ pastes after 28 days of curing at room temperature.

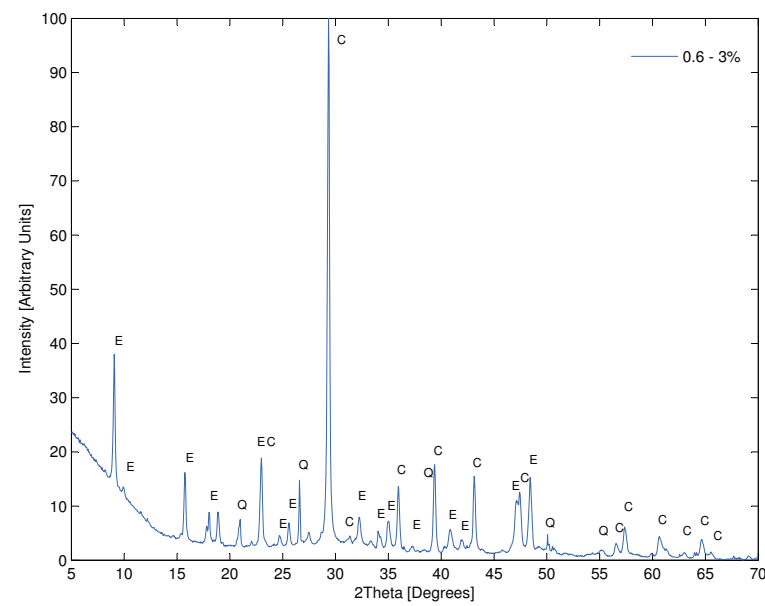

Figure 9: X-ray diffraction test performed on $0.6-3 \%$ series. C (Calcite), Q (Quartz), E (Ettringite).

\subsection{External sulphate attack (ESA)}

In order to obtain more gradual damaging parameters, ESA experiments (NIRAS and expansion) were performed. As commented before, for this experimental four series of specimens cured 28 days at room temperature varying $\mathrm{w} / \mathrm{c}$ ratio and the cement type with different $\mathrm{C}_{3} \mathrm{~A}$ contents were selected. After curing, specimens were submerged in sodium sulphate solution and were weekly monitored from 0 to 49 days.

\subsubsection{ESA expansion measures}

Figure 10 shows the expansion suffered by mortar bars exposed to ESA. White cement specimens (0.6-W and 0.5-W) present important expansions after 21 days of attack (more expansion was detected for 0.6-W respect to 0.5-W). However specimens made up with sulphur resistant cement (0.5-G and 0.6-G) did not show noticeable dimension increment. This behaviour was expected because mortars with more $\mathrm{C}_{3} \mathrm{~A}$ content and high $\mathrm{w} / \mathrm{c}$ ratios 
are more vulnerable to ESA than specimens with less $\mathrm{C}_{3} \mathrm{~A}$ content and low $w / c$ ratios.

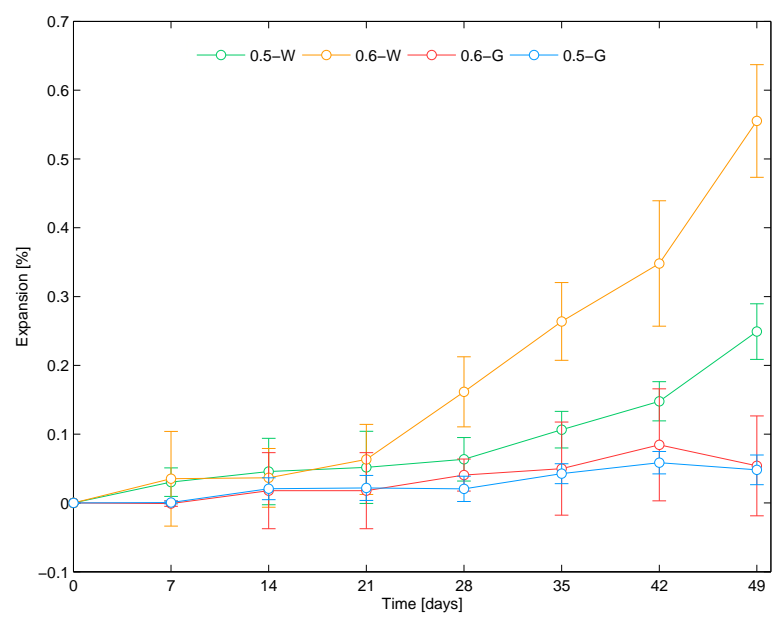

Figure 10: \% expansion of ESA specimens

\subsubsection{ESA NIRAS measures}

After obtaining expansion data from mortar bars, NIRAS tests on 40x40x160 $\mathrm{mm}^{3}$ prismatic specimens were made in order to analyse non-linear and linear acoustic resonance parameters. By means of this test, the frequency variation $f_{1 f l e x}, Q_{1 f l e x}$ variation and $\alpha_{1 \text { flex }}$ variation in function of time of exposure were obtained.

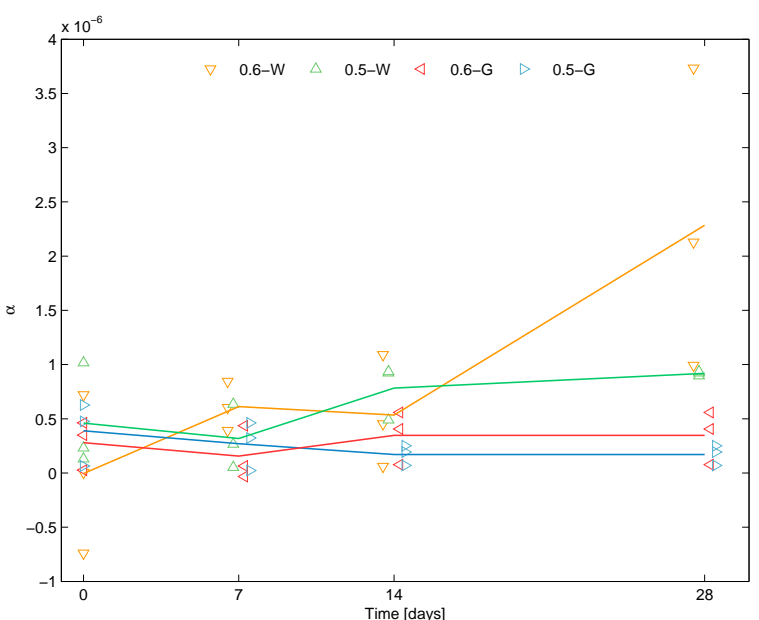

Figure 11: Calculated Non-linearity parameter $\alpha_{1 \text { flex }}$ on ESA specimens in function of immersion time in $\mathrm{Na}_{2} \mathrm{SO}_{4}$ solution.Solid lines represent mean values for calculated alpha parameter

Data was collected for $0,7,14$ and 28 days of exposure being obtained the non linearity parameter plotted in figure 11. Each point represents a single specimen from the same mixture ( 3 specimens for mixture) for the four series, and that points were separated from $\mathrm{x}$-axis tick on the graphic to make easier the reading. As can be noticed, 0.5-G and 0.6-G series do not show any increment on $\alpha$ parameter. However white cement series (0.5$\mathrm{W}$ and $0.6-\mathrm{W}$ ) began to show an increment on non-linearity parameter, specifically $0.6-\mathrm{W}$ matrix which shows 
significant increment due to notorious expansion suffered.

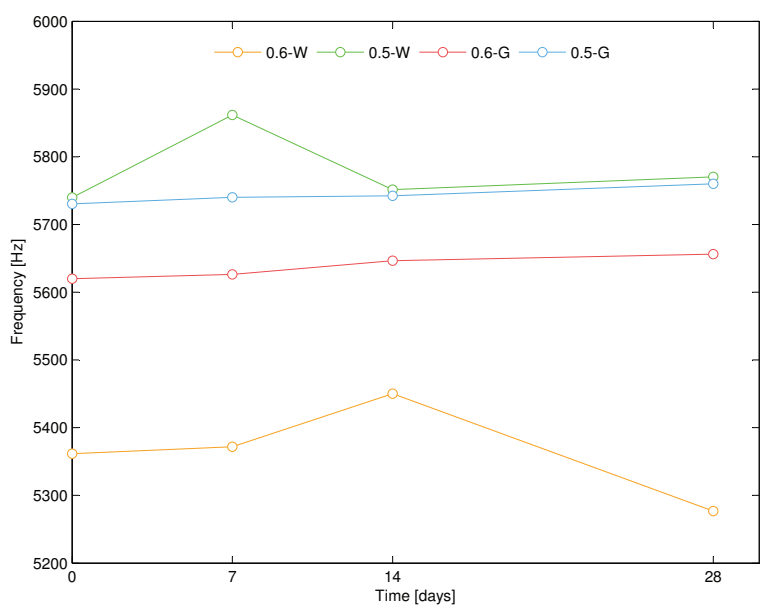

Figure 12: Frequency variation on ESA specimens

In order to obtain linear parameters from the NIRAS test, fundamental resonance frequency was plotted in figure 12. To extract mean values from the different series the signals corresponding to the high impact energy level were chosen. On that graphic can be observed analogies to the non-linear parameter variation: 0.6-W suffered an increment of its fundamental frequency until 14 days and experiment a decrement at 28 days. The rest of the series show a little increment on that parameter.

This initial increment of the frequency could be associated to a matrix densification process: second ettringe densifies the material at early ages when the pores of the specimen are empty. Later second ettringite push the pore walls damaging the material.

Similar behaviour could be observed in $Q_{1 \text { flex }}$ as show on figure 13, 0.5-W series shows an increment on $Q_{1 f l e x}$ at the beginning of the treatment and a decrement at later ages. On 0.6-W can be observed a decay from the beginning while $0.6-\mathrm{G}$ and $0.5-\mathrm{G}$ series present an increment or stable behaviour on mid-late ages.

\subsubsection{ESA microstructure analysis}

After vibrational tests on ESA specimens, microstructural analysis were performed in order to justify ettringite formation on more damaged series. The specimens were broken after 28 days of immersion and was samples from $0.6-\mathrm{G}$ and $0.6-\mathrm{W}$ series were taken for thermogravimetry and SEM studies.

Figure 14 shows SEM images of different matrices and zones of the samples. Figures 14a and 14b were from $0.6-\mathrm{G}$ specimens and show non spoiled matrix, without ettringite at x4000 and x10000 magnification. These results are in good agreement to previous data. These specimens did not show any symptom of damage. Nevertheless, figures $14 \mathrm{c}, 14 \mathrm{~d}, 14 \mathrm{e}$ and $14 \mathrm{f}$ correspond to $0.6-\mathrm{W}$ samples, and they had damage symptoms. On these micrographs it can be observed large amount of ettringite formation involving a serious matrix spoil. In 


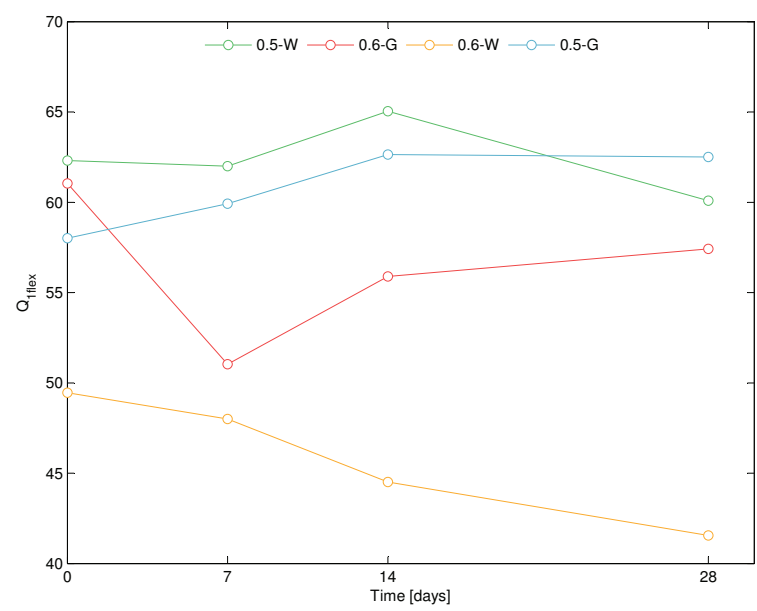

Figure 13: $Q_{1 \text { flex }}$ parameter variation on ESA specimens

figures $14 \mathrm{c}$ and $14 \mathrm{~d}$ it can be observed ettringite needles on the surface. Ettringite needles are marked throughout the matrix. In figures $14 \mathrm{e}$ and $14 \mathrm{f}$ large amount of ettringite needles formed during the attack and some hydration products are observed. 


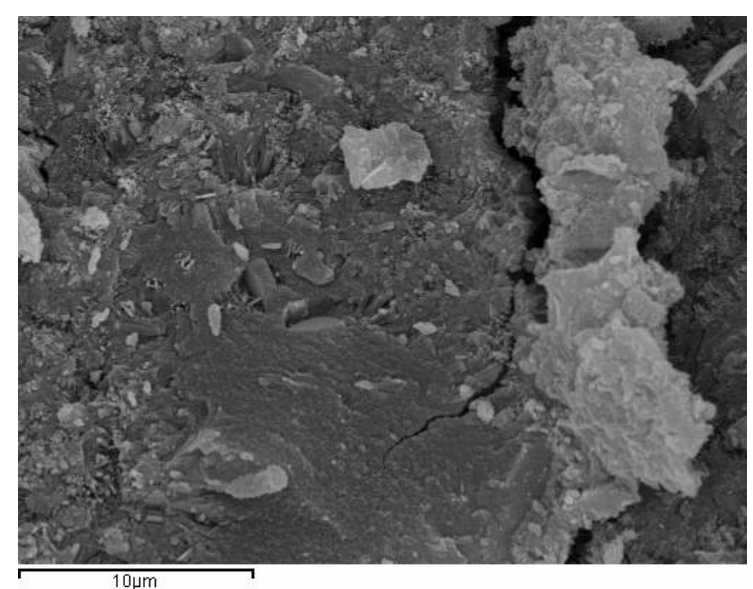

(a) Sample of 0.6-G mortar at x4000 magnification.

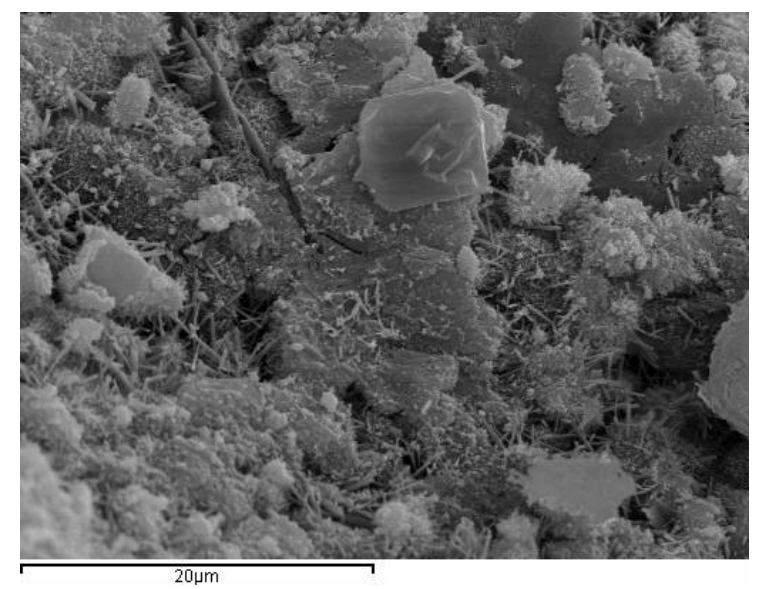

(c) Sample of 0.6-W mortar at x4000 magnification.

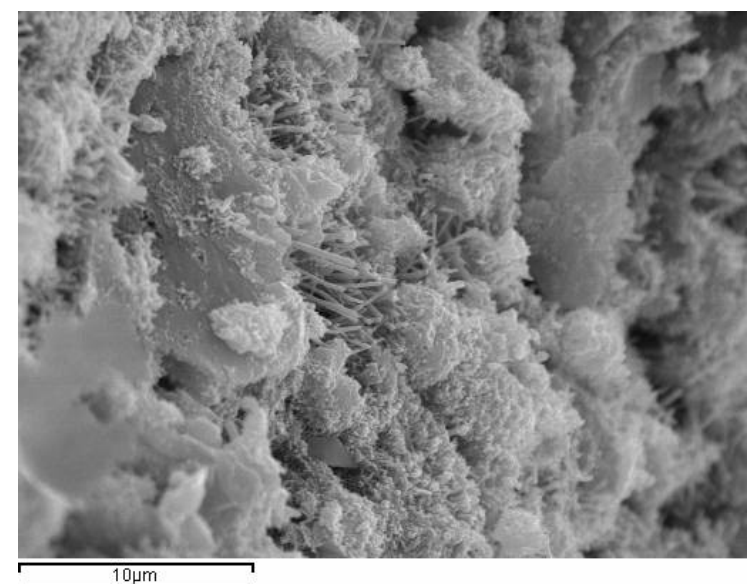

(e) Sample of 0.6-W mortar at x4000 magnification.

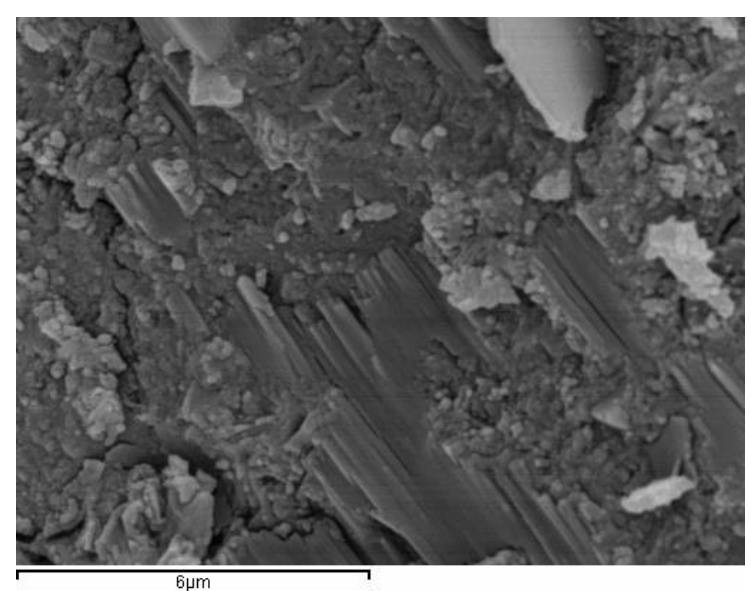

(b) Sample of 0.6-G mortar at x10000 magnification.

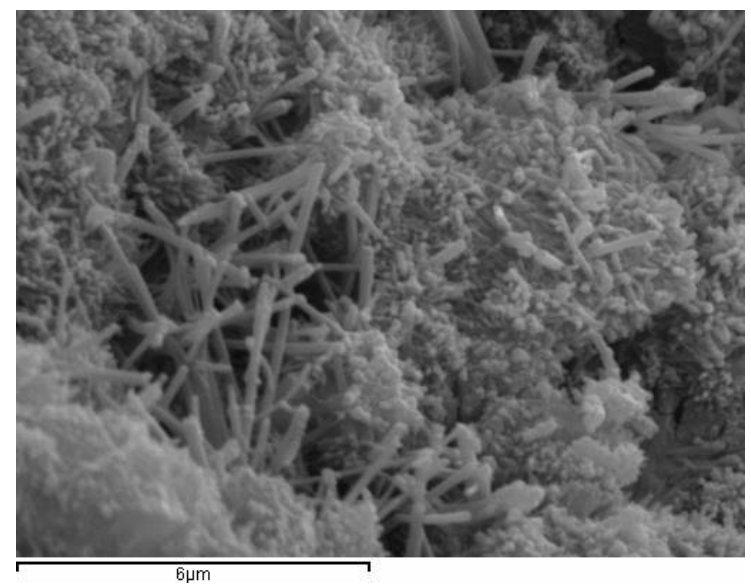

(d) Sample of 0.6-W mortar at x10000 magnification.

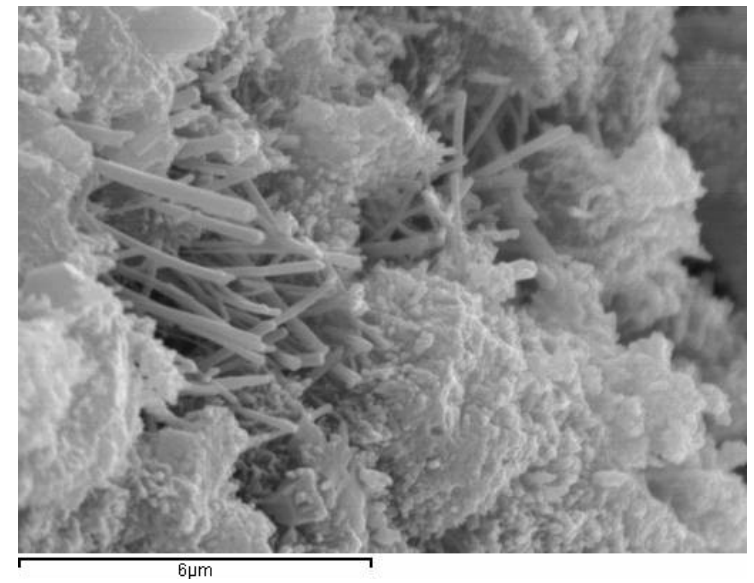

(f) Sample of 0.6-W mortar at x10000 magnification.

Figure 14: SEM images of 0.6-G and 0.6-W samples after 28 days of immersion in sodium sulphate solution 


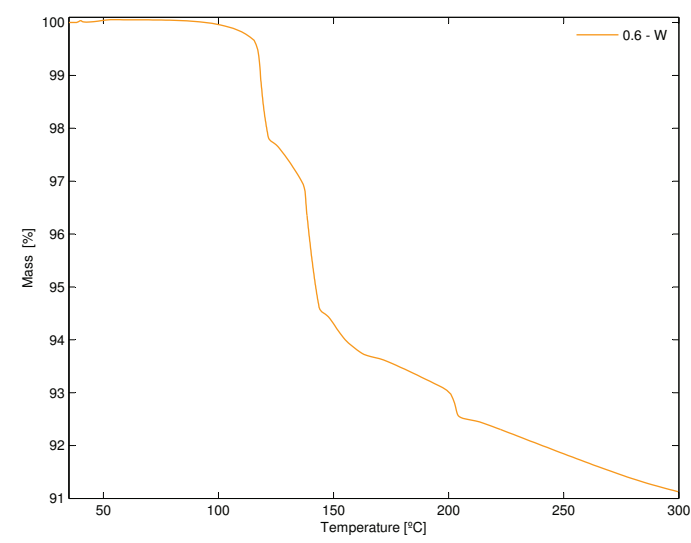

(a) TG curve of 0.6-W sample after 28 days of immersion

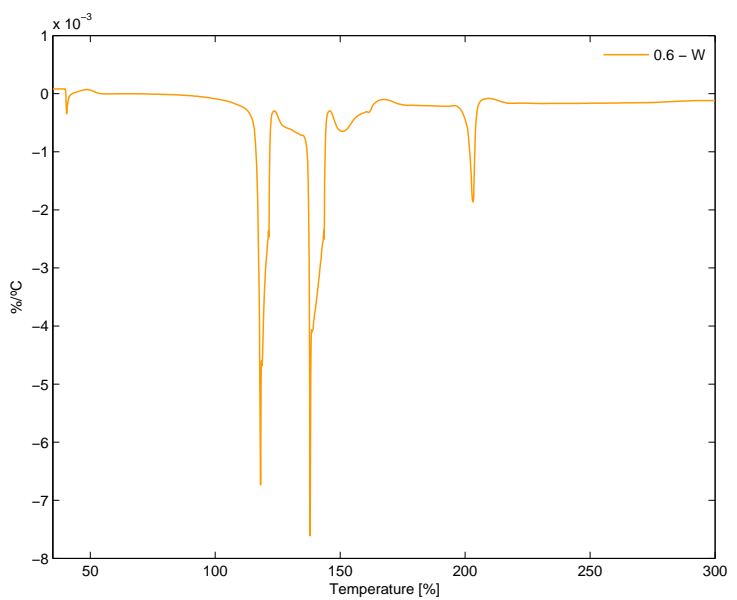

(c) DTG curve of 0.6-W sample after 28 days of immersion

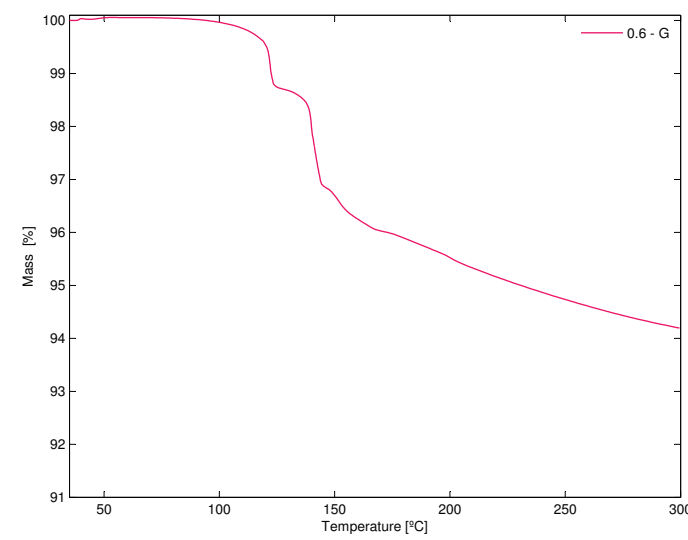

(b) TG curve of 0.6-G sample after 28 days of immersion

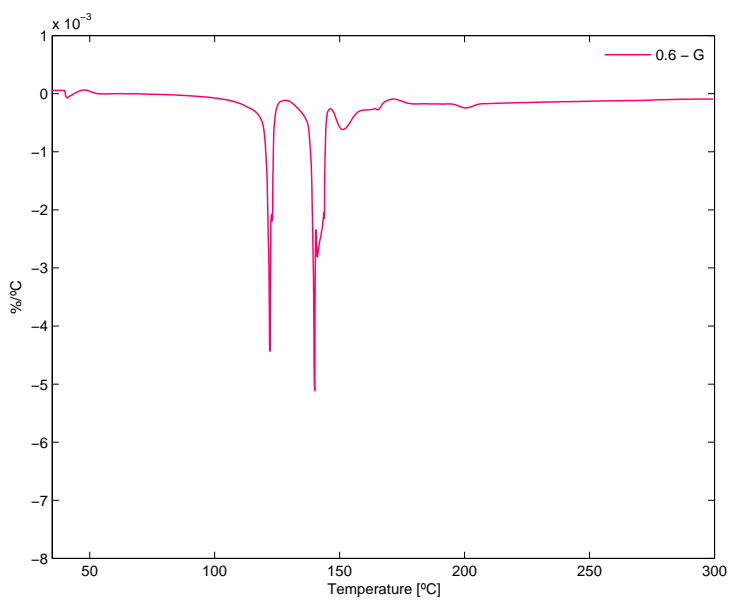

(d) DTG curve of 0.6-G sample after 28 days of immersion

Figure 15: Thermogravimetry results of mortar samples from $0.6-\mathrm{W}$ and 0.6 series. TG and DTG curves were depicted from from $35{ }^{\circ} \mathrm{C}$ to $300{ }^{\circ} \mathrm{C}$.

After SEM observations, thermogravimetry tests were performed in order to quantify the ettringite formed on 0.6-W and 0.6-G mortar specimens. To prepare these samples was used the same procedure that was previously used in ESA specimens. This analysis was carried out with a maximum resolution method (MaxRes) to be more sensitive to detect peaks on DTG when decomposition processes are very close on temperature range (case of decomposition of calcium silicate hydrates and ettringite)[23]. Ettringite peaks appears in $140{ }^{\circ} \mathrm{C}$ to $150{ }^{\circ} \mathrm{C}$ range, calcium silicate hydrates in $110{ }^{\circ} \mathrm{C}$ to $130{ }^{\circ} \mathrm{C}$ and calcium aluminosilicate hydrates in $210{ }^{\circ} \mathrm{C}$ to $220{ }^{\circ} \mathrm{C}$ $[24,25]$. These graphs are summarized in figure 15, TG (figures 15a and 15b) and DTG (figures 15c and 15d) curves were plotted. Mass loss for ettringite process was quantified for both series, resulting 3.22 \% for 0.6-W and $1.88 \%$ for $0.6-\mathrm{G}$. It can be noticed the important presence of calcium aluminosilicate hydrates for 0.6-W sample due to difference on the initial content of $\mathrm{C}_{3} \mathrm{~A}$ respect to 0.6-G.

After microstructural analysis of 0.6-W and 0.6-G series, XRD analysis was performed on 0.6-W series in order 
to detect ettringite and gypsum structures on damaged samples. In figure 16 shows XRD diffractogram for 0.6W sample. It can be noticed the presence of calcite (from limestone filler present in white Portland cement), large amount of quartz due to the sand content in the original mix and ettringite and gypsum formed during the specimen degradation process.

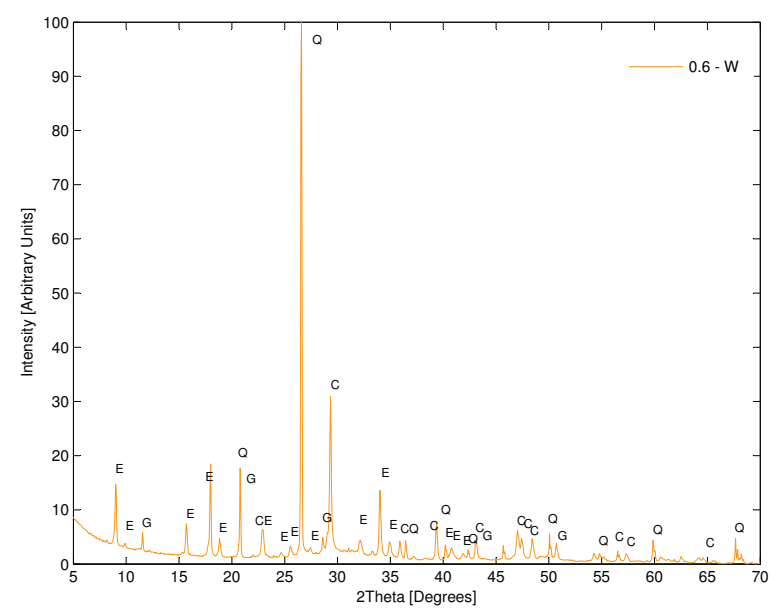

Figure 16: X-ray diffraction test performed on 0.6-W sample. C (Calcite), Q (Quartz), E (Ettringite), G (Gypsum).

\section{Conclusions}

It has been demonstrated that the NIRAS technique is suitable to evaluate external sulphate attack, which is a gradual damaging process for concrete, in order to detect damage at early ages. Monitoring the fundamental resonance frequency and $\mathrm{Q}_{\text {factor }}$ of the signals is also convenient to compare linear and non linear parameters.

Due to the harmful effect of the internal sulphate attack on mortar specimens (because high $\mathrm{CaSO}_{4}$ addition) non linear parameters could not be determined. The technique is adequate to low and mid damage ranges, when the expansion suffered by the specimens is not so high.

The obtained results from NIRAS test had a good correlationship with expansion and microstructural analysis that justify the matrix spoil by ettringite formation on damaged specimens.

\section{Acknowledgments}

The authors acknowledge the financial support of the Ministerio de Ciencia e Innovación MICINN, Spain, and FEDER funding (Ondacem Project: BIA 2010-19933). 


\section{References}

[1] M. Collepardi, A state-of-the-art review on delayed ettringite attack on concrete, Cement and Concrete Composites 25 (4-5) (2003) $401-407$.

[2] C. Ouyang, A damage model for sulfate attack of cement mortars, Cement, Concrete, and Aggregates, CCAGDP, 11(2): 92-99. 14 (1989) 10.

[3] J. Marchand, I. Odler, J. Skalny, Sulfate Attack on Concrete, Modern Concrete Technology, Taylor \& Francis, 2004.

[4] ASTM, Standard Test Method for Length Change of Hydraulic-Cement Mortars Exposed to a Sulfate Solution, ASTM Standardization News 1 (2004) 6.

[5] E. Gruyaert, P. V. den Heede, M. Maes, N. D. Belie, Investigation of the influence of blast-furnace slag on the resistance of concrete against organic acid or sulphate attack by means of accelerated degradation tests, Cement and Concrete Research 42 (1) (2012) 173 185.

[6] C. Plowman, J. Cabrera, The use of fly ash to improve the sulphate resistance of concrete, Waste Management 16 (13) (1996) 145 149.

[7] K. Veiga, A. Gastaldini, Sulfate attack on a white Portland cement with activated slag, Construction and Building Materials 34 (0) (2012) $494-503$

[8] J. Stroh, M.-C. Schlegel, E. Irassar, B. Meng, F. Emmerling, Applying high resolution SyXRD analysis on sulfate attacked concrete field samples, Cement and Concrete Research 66 (0) (2014) $19-26$.

[9] C. Xiong, L. Jiang, Z. Song, R. Liu, L. You, H. Chu, Influence of cation type on deterioration process of cement paste in sulfate environment, Construction and Building Materials 71 (0) (2014) 158 - 166.

[10] J. Zhu, M. Jiang, J. Chen, Equivalent model of expansion of cement mortar under sulphate erosion, Acta Mechanica Solida Sinica 21 (4) (2008) $327-332$.

[11] M. Gregerova, D. Vsiansky, Identification of concrete deteriorating minerals by polarizing and scanning electron microscopy, Materials Characterization 60 (7) (2009) $680-685$.

[12] V. Garnier, B. Piwakowski, O. Abraham, G. Villain, C. Payan, J. F. Chaix, Acoustic techniques for concrete evaluation: Improvements, comparisons and consistency, Construction and Building Materials 43 (0) (2013) 598 - 613.

[13] T. Gudra, B. Stawiski, Non-destructive strength characterization of concrete using surface waves, \{NDT\} \& E International 33 (1) (2000) $1-6$.

[14] V. Malhotra, N. Carino, Handbook on Nondestructive Testing of Concrete Second Edition, Taylor \& Francis, 2003.

[15] D. Breysse, G. Klysz, X. Dérobert, C. Sirieix, J. Lataste, How to combine several non-destructive techniques for a better assessment of concrete structures, Cement and Concrete Research 38 (6) (2008) $783-793$.

[16] J. A. Bogas, M. G. Gomes, A. Gomes, Compressive strength evaluation of structural lightweight concrete by non-destructive ultrasonic pulse velocity method, Ultrasonics 53 (5) (2013) $962-972$.

[17] J.-P. Balayssac, S. Laurens, G. Arliguie, D. Breysse, V. Garnier, X. Dérobert, B. Piwakowski, Description of the general outlines of the French project SENSO - Quality assessment and limits of different NDT methods, Construction and Building Materials 35 (2012) 131138.

[18] A. Jain, A. Kathuria, A. Kumar, Y. Verma, K. Murari, Combined Use of Non-Destructive Tests for Assessment of Strength of Concrete in Structure, Procedia Engineering 54 (0) (2013) $241-251$.

[19] K. J. Leśnicki, J.-Y. Kim, K. E. Kurtis, L. J. Jacobs, Characterization of $\{$ ASR $\}$ damage in concrete using nonlinear impact resonance acoustic spectroscopy technique, \{NDT\} \& E International 44 (8) (2011) $721-727$.

[20] J. Chen, A. R. Jayapalan, J.-Y. Kim, K. E. Kurtis, L. J. Jacobs, Rapid evaluation of alkali-silica reactivity of aggregates using a nonlinear resonance spectroscopy technique, Cement and Concrete Research 40 (6) (2010) 914 - 923.

[21] K. E.-A. Van Den Abeele, P. A. Johnson, A. Sutin, Nonlinear Elastic Wave Spectroscopy (NEWS) Techniques to Discern Material Damage, Part II, Research in Nondestructive Evaluation 12 (1) (2000) 17-30.

[22] A. Chaipanich, T. Nochaiya, Thermal analysis and microstructure of Portland cement-fly ash-silica fume pastes, Journal of Thermal Analysis and Calorimetry 99 (2) (2010) 487-493, ISSN 1388-6150.

[23] M. Borrachero, J. Payá, M. Bonilla, J. Monzó, The use of thermogravimetric analysis technique for the characterization of construction materials, Journal of Thermal Analysis and Calorimetry 91 (2) (2008) 503-509, ISSN 1388-6150.

[24] M. Borrachero, J. Payá, J. Monzó, The use of MaxRes for the investigation of partially hydrated Portland cement systems, Usercom 1 (2000) 15-16.

[25] J. Payá, M. Borrachero, J. Monzó, L. Soriano, M. Bonilla, Termogravimetría de alta resolución aplicada a cementos hidratados, in: X Congreso Nacional de Materiales, (2008). 